\title{
Effect of grain size for the tensile strength and the low cycle fatigue at elevated temperature of alloy 718 cogged by open die forging press
}

\author{
Y.S.Song, M.R.Lee and J.T.Kim \\ Doosan Heavy Industries \& Construction Co., Ltd., Republic of Korea
}

Keywords: Alloy 718, Low cycle fatigue, Tensile strength

\begin{abstract}
Alloy 718 was prepared through Triple melting process utilizing VIM/VAR/VAR to get the high cleanliness with low inclusion contents and then cogged by open die forging press. The grain size was controlled from ASTM No. 8.0 to 2.0 by utilizing cogging condition such as temperature, strain rate and so on, respectively.

Prior to carrying out mechanical property test, The gas content analysis, inclusion distribution by image analyzer and EDX analysis by SEM were investigated. The contents of the Nitrogen and Oxygen are $47 \mathrm{ppm}$ and $14 \mathrm{ppm}$, respectively in triple process. from the size distribution for the width and length of the non metallic Inclusions, the average size is $2 \mu \mathrm{m}$, maximum size is $14 \mu \mathrm{m}$, and minimum size is $0.3 \mu \mathrm{m}$ more or less. So the cleanliness of this processed alloy 718 was high.

To investigate effect of the grain size for the tensile strength of alloy 718 at elevated temperature, tensile strength test was done at various temperatures from RT to $649^{\circ} \mathrm{C}$. in case of the coarse grain size, the difference value between the tensile strength and yield strength was close, However, In case of the fine grain size, the difference value between the tensile strength and yield strength was bigger than that of the coarse grain size.

To study for the effect of the grain size for the low cycle fatigue life of alloy 718 at elevated temperature, low cycle fatigue test was carried out at 621 to $649^{\circ} \mathrm{C}$ with strain control ; Total strain range was $0.6 \%$ to $1.4 \%$. as expected, low cycle fatigue life, $\mathrm{N}_{\mathrm{f}}$, was short at higher strain range. But, at lower strain range, low cycle fatigue life, $\mathrm{N}_{\mathrm{f}}$, was increased relatively. Especially in case that the grain size was ASTM No. 8, low cycle fatigue life was remarkably improved compared with coarse grain size that has ASTM No. 2.

The Observation of the microstructure and fracture surface by SEM was carried out to evaluate the direct relationship among the grain size, inclusion distribution and low cycle fatigue behavior.
\end{abstract}




\section{Introduction}

Alloy 718 finds many applications because of its several attractive properties such as good corrosion resistance in a variety of aggressive environments, resistance to oxidation up to about $1,000^{\circ} \mathrm{C}$. besides, Alloy 718, with a nominal composition of $\mathrm{Ni}-19 \mathrm{Cr}-18 \mathrm{Fe}-5.5(\mathrm{Nb}+\mathrm{Ta})-3 \mathrm{Mo}-0.9 \mathrm{Ti}-$ $0.5 \mathrm{Al}(\mathrm{wt} \%)$ possess excellent high temperature mechanical properties (strength, fatigue and creep)up to $650^{\circ} \mathrm{C}$ combined with good formability and weldability and is an idea choice for various engine and generator components. This precipitation strengthened Superalloy has an FCC structure $(\gamma$ matrix) which is solid solution strengthened by, Iron, Chromium, and Molybdenum. The disc shaped, BCT Structured and ordered intermetallic compound type phase, $\gamma^{\prime \prime}$, is the principal strengthening phase in this alloy. Coherency strains are introduced during the precipitation of $\gamma^{\prime}$ (about 20 40nm) in the range of $700 \sim 900^{\circ} \mathrm{C}$. Spherical and ordered intermetallic phase, $\mathrm{Ni}_{3}(\mathrm{Ti}, \mathrm{Al})$, designated as $\gamma^{\prime}$, that is precipitated in the temperature range of $600^{\circ} \mathrm{C} \sim 700^{\circ} \mathrm{C}$ interacts with the dislocations and contributes to secondary strengthening. The alloy contains about $13 \mathrm{vol} \%$ of $\gamma^{\prime \prime}$, and $4 \mathrm{vol} \%$ of $\gamma^{\prime}$. Depending on the processing condition, delta $(\delta), \mathrm{Ni}_{3} \mathrm{Nb}$ phase can also be present. In addition, the presence of small amounts of $\mathrm{NbC}, \mathrm{TiC}$, and TiN also contribute to strengthening. Heat treatment of Alloy 718 consists of a solution treatment at high temperature followed by two step ageing at intermediate temperature. Solution temperature are chosen just below the $\delta$ solvus temperature so as to ensure dissolution of $\gamma^{\prime \prime}$ and $\gamma^{\prime}$ phase, but maintaining the fine grain size achieved by thermomechanical processing through the grain boundary pinning effect provided by $\delta$ phases. Standard heat treatment of the alloy involves solutionizing treatment of $980^{\circ} \mathrm{C} / 1 \mathrm{hr} /$ water quenched followed by ageing at $718^{\circ} \mathrm{C} / 8 \mathrm{hrs}$ and furnace cooled to $621^{\circ} \mathrm{C} / 8 \mathrm{hrs}$ and air cooled..$^{1 \sim 4)}$

\section{Experimental procedures}

The Ingot diameter of the alloy 718 was $400 \mathrm{~mm}$. it was melted and refined through triple melting process which is the Vacuum Induction Melting(VIM) followed by double Vacuum Arc Refining(VAR) to get the high cleanness with low inclusion contents. and then cogged to $150 \mathrm{~mm}$ diameter billets by open die forging utilizing the hydraulic press, 1,600ton capacity. The grain size was controlled from ASTM No. 8.0 to 2.0 by cogging condition, respectively.

The chemical composition of the alloy is presented in Table 1.

Table 1 . The chemical composition of the Alloy $718(\mathrm{wt} \%)$

\begin{tabular}{c|c|c|c|c|c|c|c|c|c|c}
\hline & $\mathrm{C}$ & $\mathrm{Ni}$ & $\mathrm{Cr}$ & $\mathrm{Mo}$ & $\mathrm{Fe}$ & $\mathrm{Ti}$ & $\mathrm{Al}$ & $\mathrm{Nb}$ & $\mathrm{Co}$ & $\mathrm{B}$ \\
\hline & 0.023 & 53.56 & 17.9 & 2.88 & 18.37 & 1.0 & 0.53 & 5.22 & 0.1 & 0.004 \\
\hline
\end{tabular}




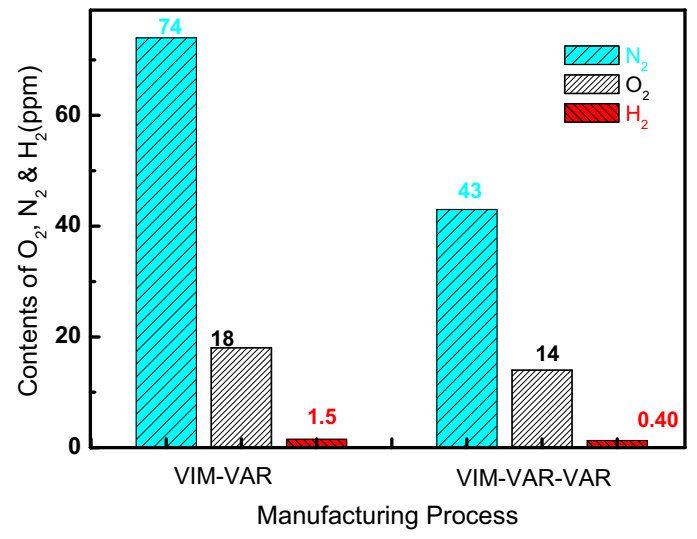

Fig. 1 The change of gas content through the triple process, VIM-VAR-VAR

Fig. 1 shows the gas content analysis results. The contents of the Nitrogen and Oxygen are 47ppm and 14ppm, respectively in Triple process.

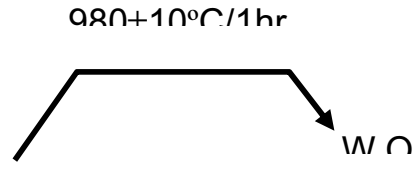

a)

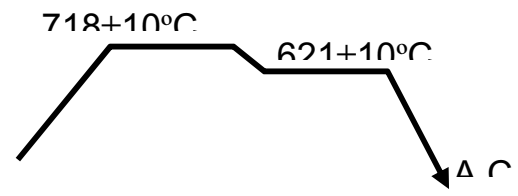

b)

Fig.2 The cycle of the heat treatment for Alloy 718

The billets were subjected to the standard solutionising and two step ageing treatment referred in Fig.2

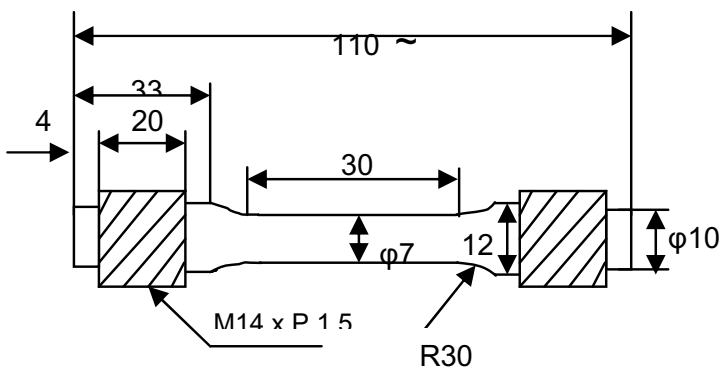

Fig. 3 Geometry of the specimen used for Low cycle fatigue test 
Prior to carrying out LCF tests, tensile tests were carried out to assess the tensile properties of the alloy from room temperature to $427^{\circ} \mathrm{C}$, and $650^{\circ} \mathrm{C}$.

All specimens for machining tensile and low cycle fatigue (LCF)were extracted from the heat treated forged billets in Longitudinal direction. The geometry of the specimen used for LCF testing is given at Fig. 3. the LCF tests were carried out using a closed loop servo controlled hydraulic machine of MTS, USA. strain controlled LCF tests were conducted in air at $621^{\circ} \mathrm{C}$ and $650^{\circ} \mathrm{C}$ with $0.004 / \mathrm{sec}$ of the strain rate and total strain range from $1.4 \%$ to $0.6 \%$. All tests were conducted using a triangular wave form at $\mathrm{R}=-1 .^{5 \sim 6)}$

\section{Results and Discussion}

\section{The cleanliness}

Fig. 4 shows that SEM micrograph and EDX analysis results for specimens as polished state. All of the non metallic inclusion is almost Carbonnitrides, Ti(C,N) type as Fig. 4 b)

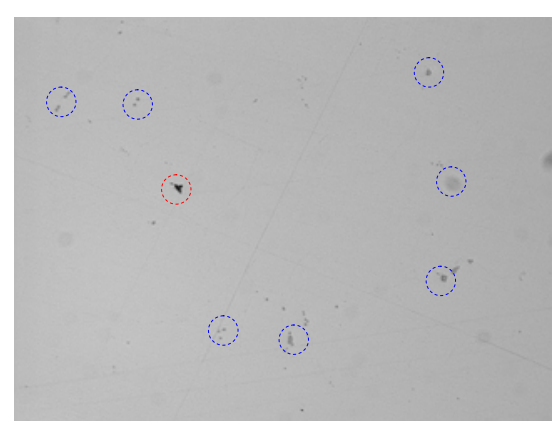

a)

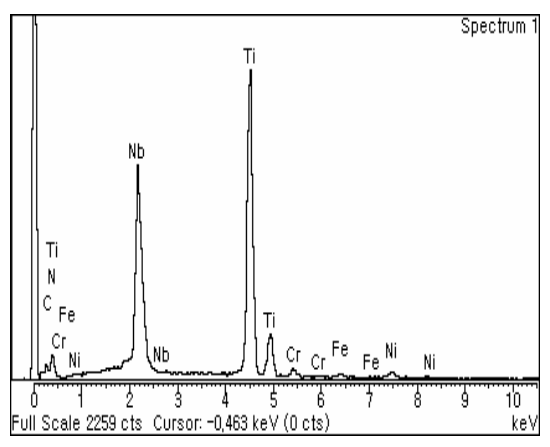

b)

Fig. 4 SEM and EDX analysis for Non metallic inclusions ${ }^{7)}$

Fig. 5 shows that the size distribution of the non metallic inclusion of the alloy 718 through triple melting process, VIM-VAR-VAR.

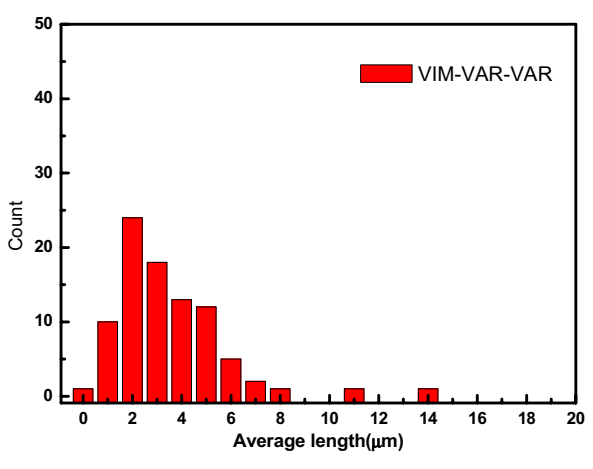

a)

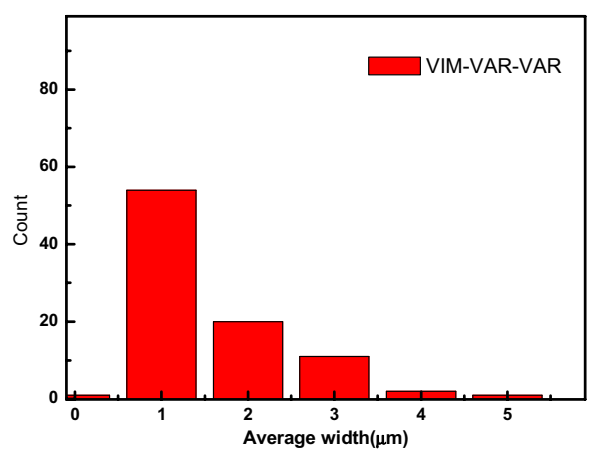

b) 


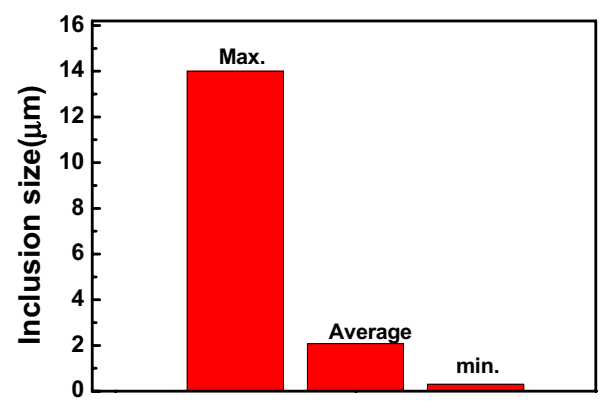

c)

Fig. 5 The size distribution of the non metallic inclusion of the alloy 718 through triple melting process, VIM-VAR-VAR ${ }^{8)}$

From the size distribution for the width and length of the non metallic Inclusions at the Fig. 5 a) and b), the average size is $2 \mu \mathrm{m}$, maximum size is $14 \mu \mathrm{m}$, and minimum size is $0.3 \mu \mathrm{m}$ more or less.

However, maximum size $14 \mu \mathrm{m}$ is just one particle counted. As a result, The cleanliness of this processed alloy 718 is remarkable.

\section{$\underline{\text { Microstructure and Grain size }}$}

A typical microstructure of the forged billet from which test specimens were extracted is shown in Fig. 3. Sample were etched using Kalling's reagent. The microstructure revealed a $\gamma$ matrix with a relatively uniform grain size ASTM 8.0 to ASTM No. 2.0 respectively without banding structure

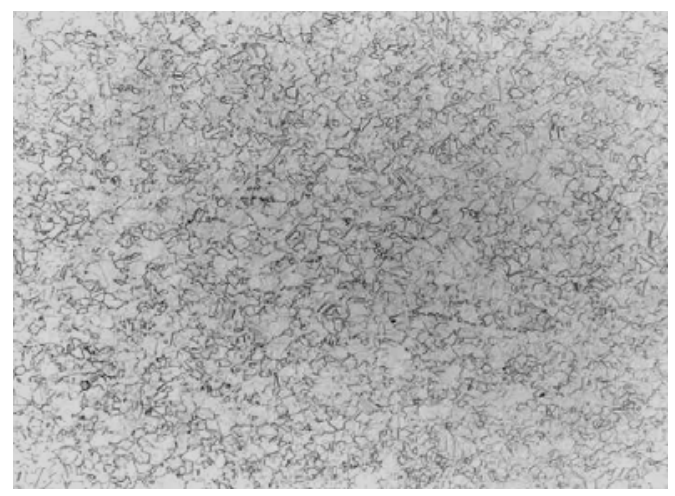

a)

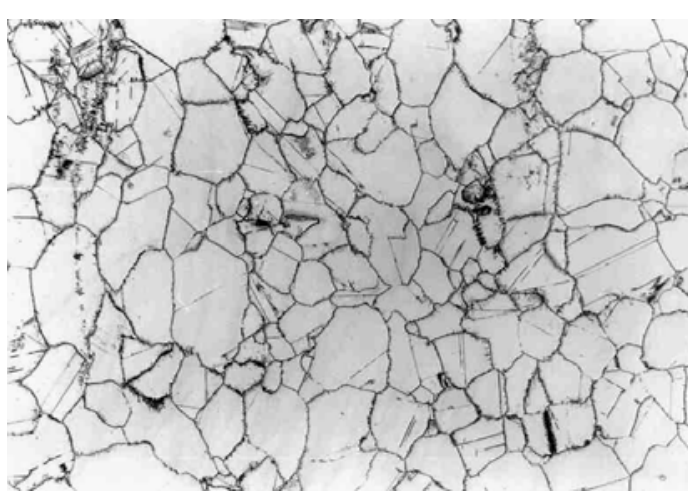

b) 


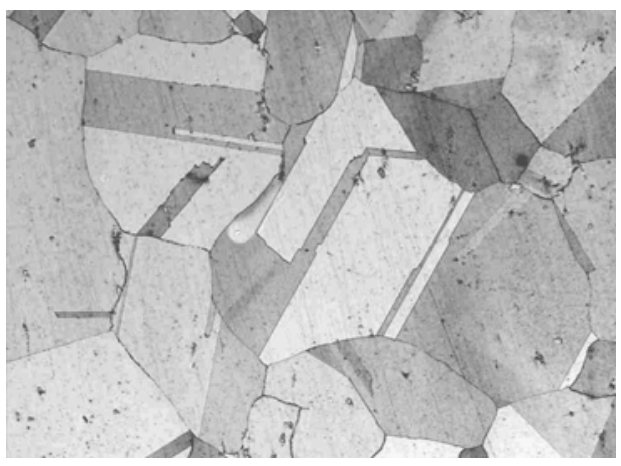

c)

Fig.6 Optical Microstructure of Alloy 718 by cogged condition $(\times 100)^{9)}$
a) ASTM No. 8
b) ASTM No.4.5
c) ASTM No. 2

\section{Tensile strength}

The yield strength and Ultimate tensile strength obtained from the tensile tests are given in Fig. 4. The $0.2 \%$ yield strength and ultimate strength were found to marginally increased with increased of the grain size in ASTM No. from 2.0 to 8.0 and the $0.2 \%$ yield strength and ultimate strength were found to remarkably decreased with increased in temperature from Room temperature to $650^{\circ} \mathrm{C}$. The drop in ultimate tensile strengths from room temperature to $427^{\circ} \mathrm{C}$ is approximately $200 \mathrm{Mpa}$ indicating excellent high temperature strength of this alloy which grain size is ASTM No. 8.0. In view of the yield strength from room temperature to $427^{\circ} \mathrm{C}$ is approximately $80 \mathrm{Mpa}$.

The drop in ultimate tensile strengths from room temperature to $650^{\circ} \mathrm{C}$ is approximately $250 \mathrm{Mpa}$ indicating excellent high temperature strength of this alloy which grain size is ASTM No. 8.0. In view of the yield strength from room temperature to $650^{\circ} \mathrm{C}$ is approximately $100 \mathrm{Mpa}$.

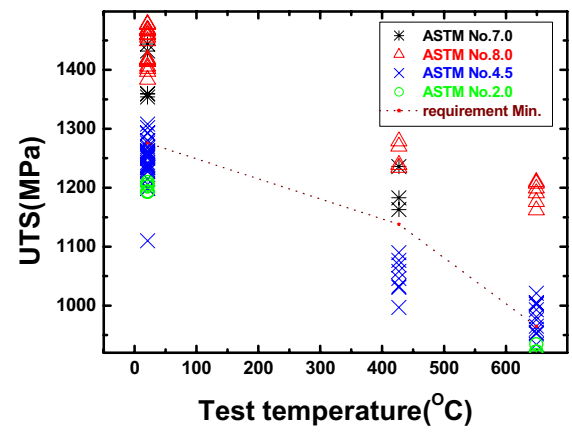

a) 


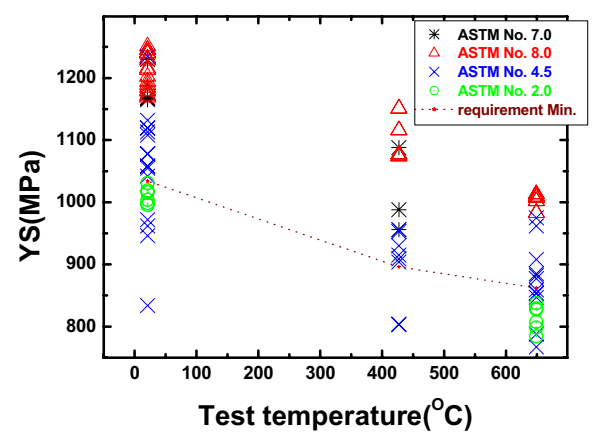

b)

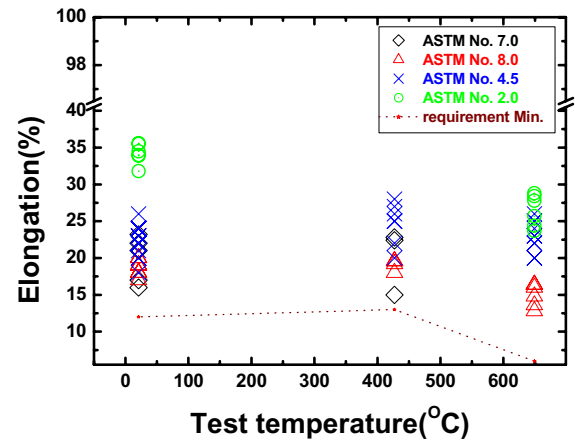

c)

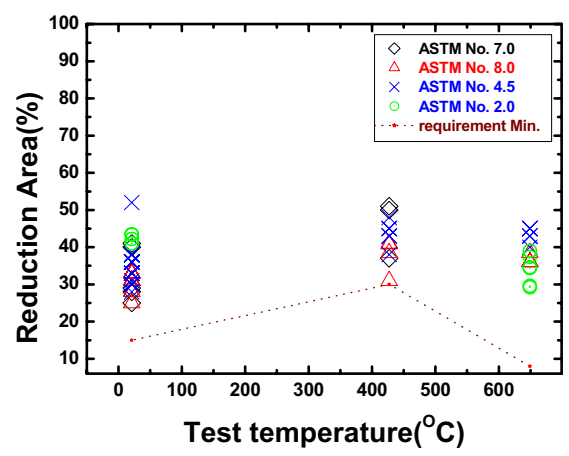

d)

Fig. 7 result of the tensile test at R.T and High temperature

The behavior of elongation shows that the average value is $18 \%$ from room temperature to $427^{\circ} \mathrm{C}$. but it is decreased to $15 \%$ at $650^{\circ} \mathrm{C}$. and The behavior of Reduction area shows that the average value is $30 \%$ at room temperature, $35 \%$ at $427^{\circ} \mathrm{C}$, and $35 \%$ at $650^{\circ} \mathrm{C}$. In case that the grain size is ASTM No. 2.0, the drop in ultimate tensile strengths from room temperature to $650^{\circ} \mathrm{C}$ is 
approximately 300Mpa indicating inferior high temperature strength of this alloy which grain size is ASTM No. 8.0. In view of the yield strength, the drop in yield from room temperature to $650^{\circ} \mathrm{C}$ is approximately $175 \mathrm{Mpa}$.

The behavior of elongation shows that the average value is $35 \%$ at room temperature, but it was decreased to $27.5 \%$ at $650^{\circ} \mathrm{C}$, and the behavior of Reduction area shows that the average value is $40 \%$ at room temperature, $35 \%$ at $650^{\circ} \mathrm{C}$.

A typical SEM fractographs of the tensile test specimens at room temperature were extracted is shown in Fig. 8. Fig. 8 revealed a dimple structure with a relatively grains size, ASTM 8.0 and ASTM No. 5 respectively.

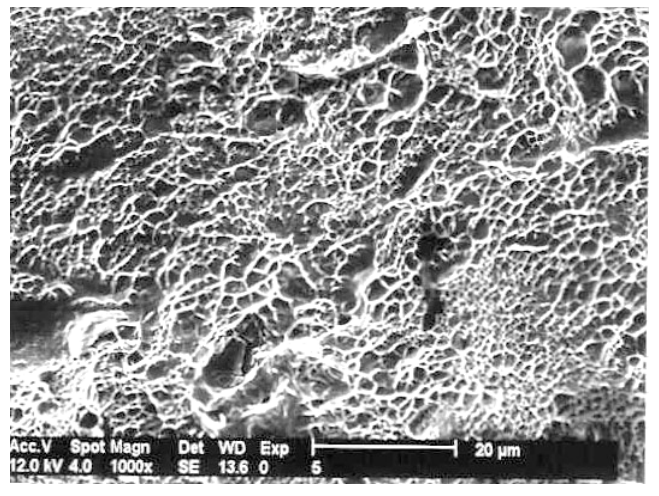

a)

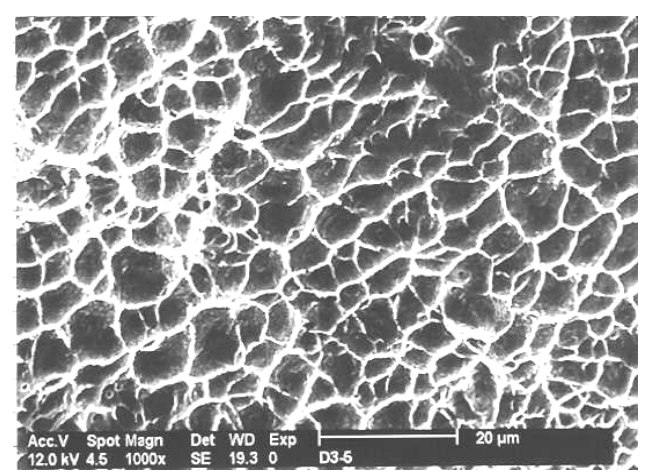

b)

Fig. 8 SEM Micrograph of fractured area after tensile test at R.T a) ASTM No.8 b) ASTM No.5

\section{$\underline{\text { LCF Properties }}$}

Fig. 9 shows the effect of strain cycling on the fatigue life of Alloy 718 at $621^{\circ} \mathrm{C}$ and $650^{\circ} \mathrm{C}$. It is evident from Fig.9 that the number of cycles to failure on total strain range at elevated temperature depends on the grain size. When grain size is ASTM No. 8, life time at a given total strain range is

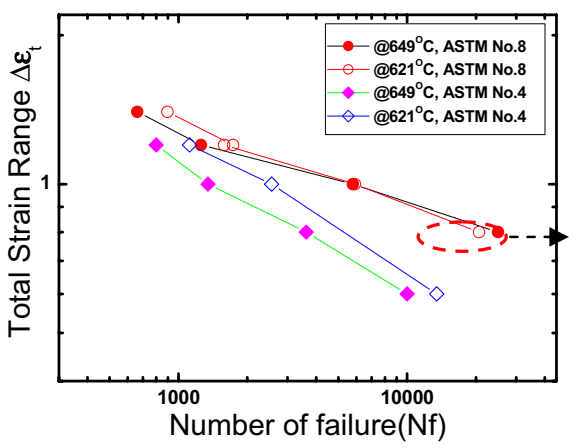

greater than ASTM No. 4.

Fig. 9 Total strain range vs number of cycles to failure, $\mathrm{N}_{\mathrm{f}}$ at $621^{\circ} \mathrm{C}, 649^{\circ} \mathrm{C}$ 


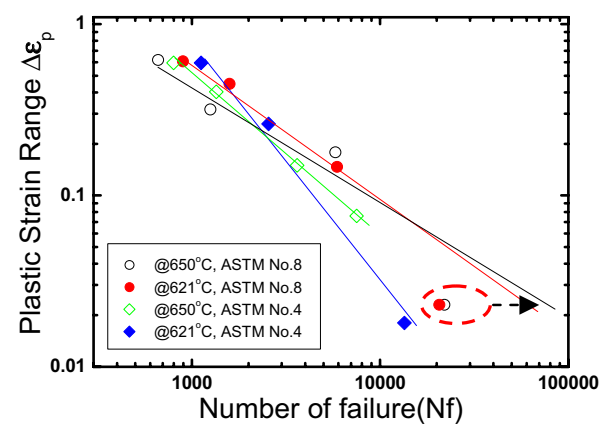

Fig. 10 Plastic strain range vs number of cycles to failure, $\mathrm{N}_{\mathrm{f}}$ at $621^{\circ} \mathrm{C}, 649^{\circ} \mathrm{C}$

In case of the ASTM No. 8, The dashed circled data points indicated that the fatigue at $621^{\circ} \mathrm{C}$ and $649^{\circ} \mathrm{C}$ with $0.8 \%$ total strain range is not occurred. However, In case of the ASTM No. 4 , the fatigue life at $621{ }^{\circ} \mathrm{C}$ and $649^{\circ} \mathrm{C}$ with $0.6 \%$ total strain is up to 13,463 and 7,500 $\mathrm{N}_{\mathrm{f}}$ cycle, respectively.

Fig. 10 shows a plot of plastic strain range vs number of cycles to failure. In case of ASTM No. 8, accumulated hysterisis loop energy per cycle for given plastic strain range is higher than that of ASTM No. 4 due to the higher yield strength of ASTM No. 8.

It is shown that fatigue life of ASTM No. 4 is similar at plastic strain range of $0.7 \%$ comparing with ASTM No. 8. in summary, the resistance to fatigue deformation increased as grain size decreased.

Low cycle fatigue test were carried out at $621^{\circ} \mathrm{C}$ with $\Delta \varepsilon_{\mathrm{t}}=1.0 \%$ to assess fatigue life according to grain size. Fig. 11 a) shows that the cycle life, $\mathrm{N}_{\mathrm{f}}$, is 2,554 cycles for grain size No 4 . there were striation patterns, brittle fractured surface and secondary cracks parallel to loading axis. while on the other, Fig. 11 b) shows that the cycle life, $\mathrm{N}_{\mathrm{f}}$, is 5,904 cycles for grain size No 8 . there were no striation pattern and ductile surfaces.

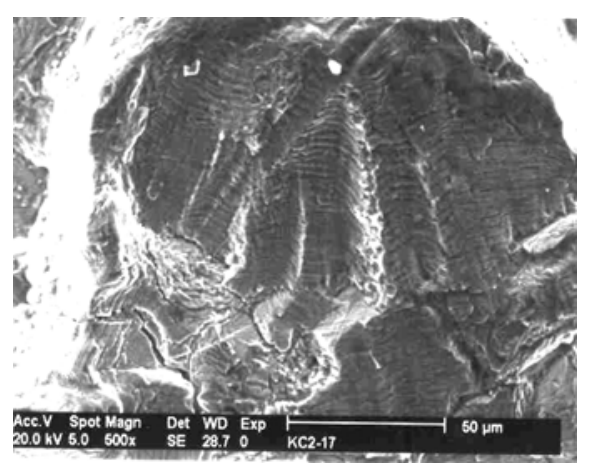

a)

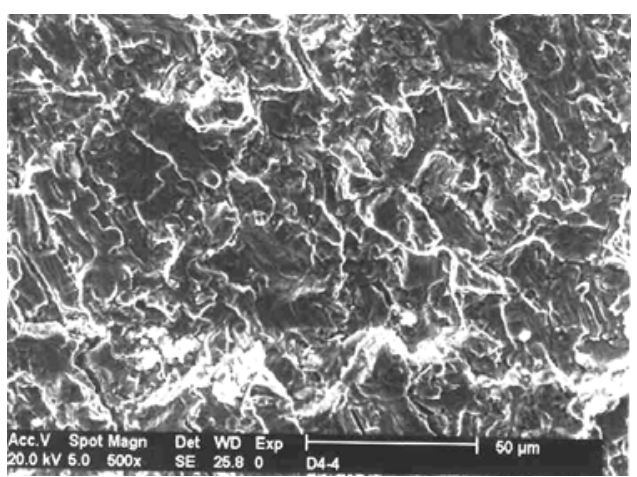

b)

Fig.11 SEM Fractographs of the fractured area after LCF test at $621^{\circ} \mathrm{C}, \Delta \varepsilon_{\mathrm{t}}=1.0 \%$. a) ASTM No. 4 , b) ASTM No. 8 
Low cycle fatigue test were carried out at $649^{\circ} \mathrm{C}$ with $\Delta \varepsilon_{\mathrm{t}}=1.0 \%$ to evaluate fatigue life according to grain size. Fig. 12 a) shows that the cycle life, $\mathrm{N}_{\mathrm{f}}$, is 1,346 cycles for grain size No 4 . there were striation pattern, but Fig. 12 b) shows that the cycle life, $N_{f}$, is 5,784 cycles for grain size No 8 . there were no striation pattern. As results of the low cycle fatigue, the less the grain size, the more low cycle fatigue life is increased because fatigue passage is longer at fine grain size than coarse grain size along to grain boundary.

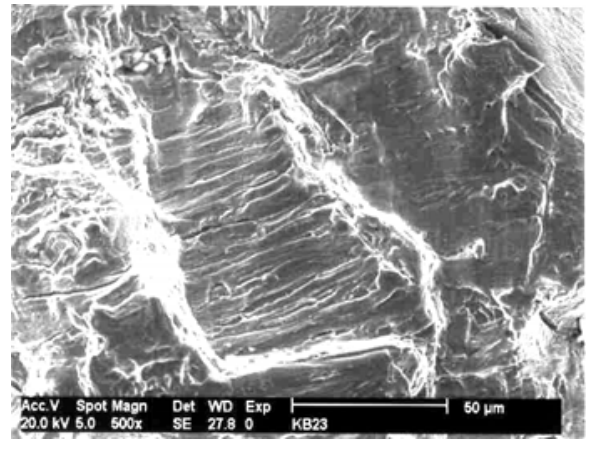

a)

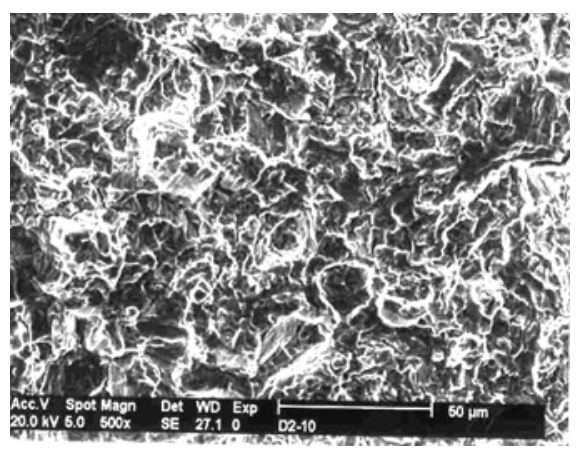

b)

Fig.12 SEM Fractographs of the fractured area after LCF test at $649^{\circ} \mathrm{C}, \Delta \varepsilon_{\mathrm{t}}=1.0 \%$. a) ASTM No. 4 , b) ASTM No. 8

\section{Conclusions}

It can be concluded that the effect of grain size on the tensile strength and Low cycle fatigue at room temperature and elevated temperature was investigated.

From tensile test results, better Tensile strength and Yield strength were shown as grain size decrease. SEM observations show that the number of dimple structure was increased with decreasing grain size. When grain size increased, Low cycle fatigue life decreased.

\section{References}

1. C.T.Sims, N.S.Stoloff and W.C.Hagel, superalloys II(New York, NY:John Wiley \& Sons, 1987), 165-188

2. R.L.SAHA,K.Gopinath,K.K.SHARMA, and M.Srinvas, Proceedings of superalloy 718, 625, 706 and derivatives, 2001. P565

3. Matthew J. Donachie and Stephen J. Donachie, ed., Superalloys : A technical guide(ASM, 2002), 58-66

4. Gary E.Korth, Proceedings of superalloys 718,625,706 and derivatives, 1991. P467

5. Gary E.Korth, Proceedings of Superalloy 718,625,706 and derivatives,1991, P471

6. Matthew J. Donachie Superalloys: A Technical guide,2002 
7. Young-Seok Song,Sung-Tae Kang and Il-Bong Kim : J. Kor. Inst. Met. \& Mater. Vol.37, No.6(1999)

8. Young-Seok Song,Sung-Tae Kang and Jeong Tae Kim : J. Kor. Inst. Met. \& Mater. Vol.39, No.10(2001)

9. Young-Seok Song, M. R. Lee and Jeong Tae Kim : Kor. Inst. Met. \& Mater 2004 spring meeting , p.3 